\title{
Clinical relevance of impaired consciousness in accidental hypothermia: A Japanese multicenter retrospective study
}

Masahiro Fukuda

Saiseikai Shiga Hospital

Masahiro Nozawa

Saiseikai Shiga Hospital

Yohei Okada ( $\nabla$ yokada-kyf@umin.ac.jp )

Kyoto Daini Hospital https://orcid.org/0000-0002-2266-476X

\section{Sachiko Morita}

Saiseikai Senri Hospital

\section{Naoki Ehara}

Kyoto First Red Cross Hospital: Kyoto Daiichi Sekijuji Byoin

Nobuhiro Miyamae

Rakuwakai Otowa Hospital

\section{Takaaki Jo}

Uji-Tokusyukai Medical Center

Yasuyuki Sumida

North Medical Center, Kyoto Prefectural University of Medicine

Nobunaga Okada

National Hospital Organisation Kyoto Medical Center: Kokuritsu Byoin Kiko Kyoto Iryo Center

Makoto Watanabe

Kyoto Prefectural University of Medicine: Kyoto Furitsu Ika Daigaku

\section{Ayumu Tsuruoka}

Kyoto Min-Iren Chuo Hospital

\section{Yoshihiro Fujimoto}

Yodogawa Christian Hospital

\section{Yoshiki Okumura}

Fukuchiyama City Hospital: Shiritsu Fukuchiyama Shimin Byoin

\section{Tetsuhisa Kitamura}

Osaka University Graduate School of Medicine

\section{Tasuku Matsuyama}

Kyoto Prefectural University of Medicine: Kyoto Furitsu Ika Daigaku 
Original Research

Keywords: body temperature change, consciousness, emergency medical services

Posted Date: April 2nd, 2021

DOI: https://doi.org/10.21203/rs.3.rs-102317/v2

License: (c) (i) This work is licensed under a Creative Commons Attribution 4.0 International License. Read Full License

Version of Record: A version of this preprint was published at Acute Medicine \& Surgery on January 1st, 2022. See the published version at https://doi.org/10.1002/ams2.730. 


\section{Abstract \\ Background}

This study aimed to investigate the association between level of impaired consciousness and severe hypothermia less than $28^{\circ} \mathrm{C}$ among accidental hypothermia. Severe accidental hypothermia (AH) is a lifethreatening condition, and early identification can enable transport to an appropriate medical facility. The Swiss staging system has been used to classify patients with $\mathrm{AH}$, but little is known regarding the association between the level of impaired consciousness and core body temperature (BT) in AH. This study aimed to clarify the association between level of impaired consciousness and core BT and determine whether the level of impaired consciousness could be used to predict severe hypothermia and in-hospital mortality among patients with $\mathrm{AH}$.

\section{Results}

The study included 505 of 572 patients in the J-point registry. Relative to mildly impaired consciousness (Glasgow coma scale (GCS) 13-15), the adjusted odds ratios for severe hypothermia were moderate (GCS9-12) 3.26 (95\% Cl: 1.69-6.25) and severe (GCS < 9) 4.68 (95\% Cl: 2.40-9.14) for severely impaired consciousness. Relative to mildly impaired consciousness (GCS 13-15), the adjusted odds ratios for inhospital mortality were moderate (GCS9-12) 1.65 (95\% Cl: 0.95-2.88) and severe (GCS < 9$) 2.10$ (95\% Cl: 1.17-3.78).

\section{Conclusions}

The level of impaired consciousness in patients with accidental hypothermia may predict severe hypothermia and in-hospital mortality.

\section{Background}

Accidental hypothermia $(\mathrm{AH})$ is a serious condition with high rates of morbidity and mortality $[1,2]$. In particular, severe hypothermia patients whose core body temperature (BT) is less than $28{ }^{\circ} \mathrm{C}$ requires intensive care management, such as extracorporeal rewarming and circulatory support, given the risks of life-threatening arrhythmia and cardiac arrest [3]. Therefore, the patient's BT can be used to guide the selection of an appropriate medical facility $[1,4]$. However, measuring core BT such as the esophageal temperature is generally unavailable in pre-hospital settings [5]. Axillary temperature is typically used in the out-of-hospital setting; however, this temperature does not necessarily accurately reflect the core BT [6]. Therefore, a simple and reliable method is needed for estimating core BT in the out-of-hospital setting.

We have traditionally used the Swiss staging system, which uses the level of consciousness and vital signs to estimate the core BT and triage the patient appropriately [1]. The Swiss staging system is 
commonly accepted worldwide; however, there is no high-quality evidence that the level of consciousness is valid for triage application [7]. In addition, little is known regarding level of consciousness guiding triage in cases of $\mathrm{AH}$. Therefore, the present study had two aims; one was to clarify the association between the level of impaired consciousness and severe hypothermia whose BT were less than $28^{\circ} \mathrm{C}$, and the other one was to determine the association between the level of impaired consciousness and inhospital mortality among patients with $\mathrm{AH}$.

This multicenter retrospective study aimed to clarify the association between the level of impaired consciousness and core BT and to determine whether the level of impaired consciousness could be used to predict severe hypothermia and in-hospital mortality among patients with $\mathrm{AH}$.

\section{Results}

The J-point registry included 572 patients between April 1, 2011 and March 31, 2016. We excluded 8 patients who were $<18$ years old, 19 patients whose BT could not be measured or was not recorded, 11 patients whose recorded BT was $>35^{\circ} \mathrm{C}, 21$ patients who were in cardiac arrest at the hospital arrival, and 9 patients with no data regarding level of consciousness. Thus, the study ultimately included 505 patients (Fig. 1).

\section{Patient characteristics}

Tables 1 and 2 show the patient characteristics. The median age was 79 years (IQR: $69-87$ years) and the median $\mathrm{BT}$ was $30.8^{\circ} \mathrm{C}$ (IQR [interquartile range]: $28.4-32.6^{\circ} \mathrm{C}$ ). Figure 2 shows the relationships between the impaired level of consciousness and BT. In-hospital mortality was recorded for $22.4 \%$ patients (113/505), including $14.6 \%$ patients with moderately impaired consciousness (31/212), $25.6 \%$ patients with mildly impaired consciousness (41/161), and $31.1 \%$ patients with severely impaired consciousness (41/132) (Fig. 3). 
Table 1

Patient characteristics according to the degree of impaired consciousness.

\begin{tabular}{|c|c|c|c|c|c|c|c|c|}
\hline \multirow{4}{*}{$\begin{array}{l}\text { Parameters, n (\%) } \\
\text { Men }\end{array}$} & \multirow{2}{*}{\multicolumn{2}{|c|}{$\begin{array}{l}\text { All patients } \\
(\mathrm{N}=505)\end{array}$}} & \multicolumn{6}{|c|}{ Degree of impaired consciousness } \\
\hline & & & \multirow{2}{*}{\multicolumn{2}{|c|}{$\begin{array}{l}\text { Mild } \\
\text { [GCS > 12] } \\
(\mathrm{N}=212)\end{array}$}} & \multirow{2}{*}{\multicolumn{2}{|c|}{$\begin{array}{l}\text { Moderate } \\
\text { [GCS 9-12] } \\
(\mathrm{N}=161)\end{array}$}} & \multirow{2}{*}{\multicolumn{2}{|c|}{$\begin{array}{l}\text { Severe } \\
{[\text { GCS < }]} \\
(N=132)\end{array}$}} \\
\hline & & & & & & & & \\
\hline & 255 & $(50.5 \%)$ & 110 & $(51.9 \%)$ & 67 & $(41.6 \%)$ & 78 & $(59.1 \%)$ \\
\hline Age, years & 79 & {$[68-87]$} & 78 & {$[67-87]$} & 82 & [70-88] & 77.5 & [66-87] \\
\hline $18-64$ years & 99 & $(19.6 \%)$ & 42 & $(19.8 \%)$ & 25 & $(15.5 \%)$ & 32 & $(24.2 \%)$ \\
\hline $65-74$ years & 83 & $(16.4 \%)$ & 38 & $(17.9 \%)$ & 23 & $(14.3 \%)$ & 22 & $(16.7 \%)$ \\
\hline$\geq 75$ years & 323 & $(64.0 \%)$ & 132 & $(62.3 \%)$ & 113 & $(70.2 \%)$ & 78 & $(59.1 \%)$ \\
\hline \multicolumn{9}{|l|}{ ADLs } \\
\hline Independent & 350 & $(69.3 \%)$ & 150 & $(70.8 \%)$ & 104 & $(64.6 \%)$ & 96 & $(72.7 \%)$ \\
\hline Modified dependence & 123 & $(24.4 \%)$ & 48 & $(22.6 \%)$ & 49 & $(30.4 \%)$ & 26 & $(19.7 \%)$ \\
\hline Complete dependence & 30 & $(5.9 \%)$ & 12 & $(5.7 \%)$ & 8 & $(5.0 \%)$ & 10 & $(7.6 \%)$ \\
\hline Unknown & 2 & $(0.4 \%)$ & 2 & $(0.9 \%)$ & 0 & $(0.0 \%)$ & 0 & $(0.0 \%)$ \\
\hline \multicolumn{9}{|l|}{ Medical history } \\
\hline Cardiovascular & 226 & $(44.8 \%)$ & 95 & $(44.8 \%)$ & 78 & $(48.4 \%)$ & 53 & $(40.2 \%)$ \\
\hline Neurological & 90 & $(17.8 \%)$ & 37 & $(17.5 \%)$ & 28 & $(17.4 \%)$ & 25 & $(18.9 \%)$ \\
\hline Endocrine & 128 & $(25.3 \%)$ & 53 & $(25.0 \%)$ & 35 & $(21.7 \%)$ & 40 & $(30.3 \%)$ \\
\hline Psychiatric & 110 & $(21.8 \%)$ & 41 & $(19.3 \%)$ & 35 & $(21.7 \%)$ & 34 & $(25.8 \%)$ \\
\hline Malignant & 16 & $(3.2 \%)$ & 7 & $(3.3 \%)$ & 4 & $(2.5 \%)$ & 5 & $(3.8 \%)$ \\
\hline Dementia & 104 & $(20.6 \%)$ & 48 & $(22.6 \%)$ & 38 & $(23.6 \%)$ & 18 & $(13.6 \%)$ \\
\hline Unknown & 7 & $(1.4 \%)$ & 3 & $(1.4 \%)$ & 3 & $(1.9 \%)$ & 1 & $(0.8 \%)$ \\
\hline
\end{tabular}


Table 2

Patient data according to the degree of impaired consciousness.

\begin{tabular}{|c|c|c|c|c|c|c|c|c|}
\hline \multirow{4}{*}{$\begin{array}{l}\text { Parameters } \\
\\
\text { Temperature }\end{array}$} & \multirow{2}{*}{\multicolumn{2}{|c|}{$\begin{array}{l}\text { All patients } \\
(\mathrm{N}=505)\end{array}$}} & \multicolumn{6}{|c|}{ Degree of impaired consciousness } \\
\hline & & & \multirow{2}{*}{\multicolumn{2}{|c|}{$\begin{array}{l}\text { Mild } \\
\text { [GCS > 12] } \\
(N=212)\end{array}$}} & \multirow{2}{*}{\multicolumn{2}{|c|}{$\begin{array}{l}\text { Moderate } \\
\text { [GCS 9-12] } \\
(\mathrm{N}=161)\end{array}$}} & \multirow{2}{*}{\multicolumn{2}{|c|}{$\begin{array}{l}\text { Severe } \\
{[\text { GCS < } 9]} \\
(N=132)\end{array}$}} \\
\hline & & & & & & & & \\
\hline & 30.8 & $\begin{array}{l}{[28.4-} \\
32.6]\end{array}$ & 31.8 & $\begin{array}{l}{[30.1-} \\
33.1]\end{array}$ & 29.8 & $\begin{array}{l}{[28.0-} \\
32.3]\end{array}$ & 29.7 & $\begin{array}{l}{[26.2-} \\
32.0]\end{array}$ \\
\hline $34.9-32^{\circ} \mathrm{C}$ & 180 & $(35.6 \%)$ & 102 & $(48.1 \%)$ & 44 & $(27.3 \%)$ & 34 & $(25.8 \%)$ \\
\hline $31.9-28^{\circ} \mathrm{C}$ & 223 & $(44.2 \%)$ & 93 & $(43.9 \%)$ & 77 & $(47.8 \%)$ & 53 & $(40.2 \%)$ \\
\hline $27.9-24^{\circ} \mathrm{C}$ & 88 & $(17.4 \%)$ & 16 & $(7.5 \%)$ & 34 & $(21.1 \%)$ & 38 & $(28.8 \%)$ \\
\hline$\leq 23.9^{\circ} \mathrm{C}$ & 14 & $(2.8 \%)$ & 1 & $(0.5 \%)$ & 6 & $(3.7 \%)$ & 7 & $(5.3 \%)$ \\
\hline \multicolumn{9}{|l|}{ Heart rate } \\
\hline$\geq 50$ beats $/ \mathrm{min}$ & 379 & $(75.1 \%)$ & 173 & $(81.6 \%)$ & 117 & $(72.7 \%)$ & 89 & $(67.4 \%)$ \\
\hline $31-49$ beats/min & 107 & $(21.2 \%)$ & 36 & $(17.0 \%)$ & 39 & $(24.2 \%)$ & 32 & $(24.2 \%)$ \\
\hline$\leq 30$ beats $/ \mathrm{min}$ & 19 & $(3.7 \%)$ & 3 & $(1.4 \%)$ & 5 & $(3.1 \%)$ & 11 & $(8.4 \%)$ \\
\hline \multicolumn{9}{|l|}{ Systolic blood pressure } \\
\hline$\geq 90 \mathrm{mmHg}$ & 370 & $(73.3 \%)$ & 178 & $(84.0 \%)$ & 114 & $(70.8 \%)$ & 78 & $(59.1 \%)$ \\
\hline $61-89 \mathrm{mmHg}$ & 85 & $(16.8 \%)$ & 28 & $(13.2 \%)$ & 29 & $(18.0 \%)$ & 28 & $(21.2 \%)$ \\
\hline$\leq 60 \mathrm{mmHg}$ & 50 & $(9.9 \%)$ & 6 & $(2.8 \%)$ & 18 & $(10.2 \%)$ & 26 & $(19.7 \%)$ \\
\hline \multicolumn{9}{|l|}{ Laboratory findings } \\
\hline $\mathrm{pH}$ & 7.32 & $\begin{array}{l}\text { [7.25- } \\
7.37]\end{array}$ & 7.34 & $\begin{array}{l}{[7.29-} \\
7.38]\end{array}$ & 7.31 & $\begin{array}{l}{[7.24-} \\
7.38]\end{array}$ & 7.28 & $\begin{array}{l}{[7.19-} \\
7.35]\end{array}$ \\
\hline Lactate (mmol/L) & 2.7 & $\begin{array}{l}{[1.3-} \\
5.85]\end{array}$ & 2.4 & $\begin{array}{l}{[1.3-} \\
4.6]\end{array}$ & 3.2 & $\begin{array}{l}{[1.55-} \\
7.55]\end{array}$ & 2.7 & $\begin{array}{l}{[1.0-} \\
6.55]\end{array}$ \\
\hline Sodium (mmol/L) & 140 & $\begin{array}{l}{[135-} \\
143]\end{array}$ & 139 & $\begin{array}{l}{[136-} \\
143]\end{array}$ & 140 & $\begin{array}{l}{[136-} \\
143]\end{array}$ & 139 & $\begin{array}{l}{[134-} \\
143]\end{array}$ \\
\hline $\begin{array}{l}\text { Potassium } \\
(\mathrm{mmol} / \mathrm{L})\end{array}$ & 4.0 & $\begin{array}{l}{[3.6-} \\
4.6]\end{array}$ & 4.0 & $\begin{array}{l}{[3.6-} \\
4.5]\end{array}$ & 4.0 & $\begin{array}{l}{[3.6-} \\
4.9]\end{array}$ & 4.3 & $\begin{array}{l}{[3.5-} \\
4.7]\end{array}$ \\
\hline \multicolumn{9}{|l|}{ Comorbidities } \\
\hline Infection & 161 & $(31.9 \%)$ & 56 & $(26.4 \%)$ & 50 & $(31.1 \%)$ & 55 & $(41.7 \%)$ \\
\hline
\end{tabular}




\begin{tabular}{|c|c|c|c|c|c|c|c|c|}
\hline \multirow{4}{*}{\begin{tabular}{|l} 
Parameters \\
Stroke
\end{tabular}} & \multirow{2}{*}{\multicolumn{2}{|c|}{$\begin{array}{l}\text { All patients } \\
(\mathrm{N}=505)\end{array}$}} & \multicolumn{6}{|c|}{ Degree of impaired consciousness } \\
\hline & & & \multirow{2}{*}{\multicolumn{2}{|c|}{$\begin{array}{l}\text { Mild } \\
{[G C S>12]} \\
(N=212)\end{array}$}} & \multirow{2}{*}{\multicolumn{2}{|c|}{$\begin{array}{l}\text { Moderate } \\
\text { [GCS 9-12] } \\
(\mathrm{N}=161)\end{array}$}} & \multirow{2}{*}{\multicolumn{2}{|c|}{$\begin{array}{l}\text { Severe } \\
{[G C S<9]} \\
(N=132)\end{array}$}} \\
\hline & & & & & & & & \\
\hline & 21 & $(4.2 \%)$ & 8 & $(3.8 \%)$ & 2 & $(1.2 \%)$ & 11 & $(8.3 \%)$ \\
\hline Brain trauma & 17 & $(3.4 \%)$ & 8 & $(3.8 \%)$ & 5 & $(3.1 \%)$ & 4 & $(3.0 \%)$ \\
\hline Intoxication & 69 & $(13.7 \%)$ & 21 & $(9.9 \%)$ & 28 & $(17.4 \%)$ & 20 & $(15.2 \%)$ \\
\hline Hypoglycemia & 38 & $(7.5 \%)$ & 13 & $(6.1 \%)$ & 11 & $(6.8 \%)$ & 15 & $(11.4 \%)$ \\
\hline $\begin{array}{l}\text { Electrolyte } \\
\text { abnormalities }\end{array}$ & 13 & $(2.6 \%)$ & 1 & $(0.5 \%)$ & 7 & $(4.3 \%)$ & 5 & $(3.8 \%)$ \\
\hline Uremia & 46 & $(9.1 \%)$ & 12 & $(5.7 \%)$ & 17 & $(10.6 \%)$ & 17 & $(12.9 \%)$ \\
\hline
\end{tabular}

\section{Primary analysis}

Relative to mild groups (GCS13-15), the crude odds ratio (COR) values for severe hypothermia were as follows; moderate group (GCS9-12) 3.79 (95\% Cl: 2.06-6.99) and severe group (GCS < 9) 5.93 (95\% Cl: 3.22-10.95). Relative to mild groups (GCS13-15), the adjusted odds ratio (AOR) values for severe hypothermia were as follows; moderate group (GCS9-12) 3.26 (95\% Cl: 1.69-6.25) and severe group (GCS < 9) 4.68 (95\% Cl: 2.40-9.14) (Fig. 4). For predicting severe hypothermia, severely impaired consciousness (GCS < 9 ) provided a sensitivity of 0.44 (95\% Cl: $0.34-0.54)$, specificity of $0.78(95 \% \mathrm{Cl}$ : 0.74-0.82), a positive likelihood ratio (LR) of 2.04, and a negative LR of 0.71 . For predicting severe hypothermia, the combination of moderately (GCS9-12) or severely impaired consciousness (GCS < 9 ) provided a sensitivity of 0.83 (95\% Cl: $0.76-0.91)$, specificity of $0.48(95 \% \mathrm{Cl}: 0.44-0.53)$, a positive LR of 1.61 , and a negative LR of 0.34 .

\section{Secondary analysis}

Relative to mild groups (GCS13-15), the COR values for in-hospital mortality were as follows; moderate group (GCS9-12) 1.98 (95\% Cl: 1.18-3.34) and (GCS < 9) 2.62 (95\% Cl: 1.54-4.45) for severely impaired consciousness. Relative to mildly impaired consciousness, the AOR values for in-hospital mortality were moderate group (GCS9-12) 1.65 (95\% Cl: 0.95-2.88) and severe group (GCS < 9$) 2.10$ (95\% Cl: 1.17-3.78) (Fig. 4).

\section{Discussion}




\section{Key findings}

This multi-center retrospective study revealed the association between the level of impaired consciousness and severe hypothermia among patients with $\mathrm{AH}$. These results might be useful for predicting severe hypothermia and in-hospital mortality among patients with $\mathrm{AH}$.

\section{Strength and previous findings}

We believe that our study has two important strengths relative to previous studies. First, we performed a multi-center study with a large sample of patients, while most previous studies have examined a small sample of patients at a single center. Moreover, although some reports have addressed the validity of the Swiss staging system $[7,15]$, no studies have directly analyzed the association between the level of impaired consciousness and core BT among patients with $\mathrm{AH}$. Second, we evaluated patients who developed $\mathrm{AH}$ in urban areas, while previous studies have typically evaluated $\mathrm{AH}$ occurring in cold climates, such as the Alps $[16,17]$. In contrast, we evaluated a predominantly urban sample that included a large number of elderly people with underlying diseases, which suggests that our results may be generalizable to urban areas with aging populations.

\section{Interpretation}

The results of this study could be attributed to the following mechanisms. First, we suggest that a decrease in core BT might reduce brain activity and lead to a decreased level of consciousness. Previous studies in rats have shown that a decrease in BT causes a decrease in the permeability of the blood-brain barrier, which reduces the delivery of energy sources to brain cells [18]. Furthermore, studies of humans under surgical anesthesia with hypothermic circulatory arrest revealed reduced brain oxygen consumption [19] and suppressed electroencephalography that was correlated with a decrease in core BT [20]. Thus, it seems reasonable to assume that the level of impaired consciousness in severe hypothermia is caused by a decrease in brain activity that is related to a decreased core BT.

\section{Clinical implications}

We believe that this study has two clinical implications. First, it potentially may facilitate the prediction of severe hypothermia for patients with suspected $\mathrm{AH}$ in the out-of-hospital setting, where esophageal or rectal measures of core BT are unrealistic. This prediction could guide the transportation of patients to an appropriate medical facility where they can undergo invasive rewarming via extracorporeal membrane oxygenation. Furthermore, it may possibly be useful to treat these patients carefully during transport to avoid ventricular fibrillation. Second, the level of impaired consciousness may be useful for prognostication and guiding decision-making regarding whether to administer or withdraw intensive treatment. Therefore, our findings may be useful in both out-of-hospital and emergency care settings.

\section{Limitations}

The present study has some limitations. First, we excluded patients without information regarding the level of impaired consciousness, which might be a source of selection bias. Second, the retrospective 
design suggests that there was variability in the measurement site and timing of the core BT measurement. Third, evaluation of level of consciousness requires some skills and experience [21, 22]. Although we believe that the medical staff at the participating emergency departments were likely welltrained, the validity of the assessments is also unclear and there is a risk of measurement bias. Fourth, we did not obtain detailed information regarding the causes of $\mathrm{AH}$, which may suggest that there was unmeasured confounding. Fifth, this study was conducted in an urban population in Japan, which has a high proportion of elderly people and may not be generalizable to $\mathrm{AH}$ patients in other regions. Therefore, further research is needed to validate our results and address these issues.

\section{Conclusions}

This multi-center retrospective study of 505 patients with AH suggests that the level of impaired consciousness might be useful for predicting severe hypothermia and in-hospital mortality. Therefore, in an urban out-of-hospital emergency settings, the level of impaired consciousness may be helpful for triaging the patients to an appropriate hospital.

\section{Methods}

\section{Study design and setting}

This multi-center retrospective study evaluated the J-point registry database [2, 8], which has been previously described $[2,8-10]$. The registry includes data regarding patients with an unknown BT or those with a $\mathrm{BT}$ of $\leq 35.0^{\circ} \mathrm{C}$ who were treated for $\mathrm{AH}$ in emergency departments between April 1, 2011 and March 31,2016 . The registry contains data from eight critical care centers and four non-critical care centers in the Osaka, Kyoto, and Shiga prefectures of Japan. In Japan, a critical care center generally serves a population of 500,000 people and is certified by the Ministry of Health, Labor and Welfare of Japan to provide $24 \mathrm{~h}$ /day care to patients with severe trauma, severe shock, stroke, and acute coronary syndrome. The median number of patients who visit the emergency department at each facility is 19,651 (IQR: 13,281-27,554). Patients were excluded from the J-point registry if they or their family members explicitly refused to be included in the registry. For the present study, clinical data were retrospectively extracted by emergency physicians using a predefined data extraction sheet. The J-point registry protocol and retrospective analysis of anonymized data were approved by the ethics committee of Saiseikai Shiga Hospital (approval ID: 244). Each hospital also approved the registry protocol as necessary.

\section{Study patients}

This study included the patients from the J-point registry who were $>18$ years old and diagnosed with hypothermia. Based on a previous report [1], hypothermia was defined as having a core BT of $\leq 35^{\circ} \mathrm{C}$. Patients were excluded if they had cardiac arrest at the hospital arrival or had no record of consciousness level.

\section{Data collection}


We obtained clinical data from the J-point registry database regarding age, sex, activities of daily living $(A D L)$, medical history, vital signs at hospital arrival, blood test findings, comorbidities, and in-hospital mortality. Age was categorized as 18-64 years, 65-74 years, and $\geq 75$ years, based on age definitions reported from government statistical methods [11]. We also categorized the vital signs based on the Japan Fire and Disaster Management Agency protocol for triage [12]. Patients whose systolic blood pressure was difficult to measure were assigned a value of $\leq 60 \mathrm{mmHg}$ and patients whose heart rate was difficult to measure were assigned a value of $\leq 30$ beats $/ \mathrm{min}$. Data regarding respiratory status were not included in the analysis, as it is difficult to measure percutaneous arterial oxygen saturation in patients with hypothermia [13] and many patients were missing data regarding their respiratory rate.

\section{Exposure}

The primary exposure of interest was the level of consciousness at hospital arrival. The level of impaired consciousness was evaluated using the Glasgow Coma Scale (GCS) and the results were classified three groups as mild (GCS of 13-15), moderate (GCS of 9-12), or severe (GCS of 3-8). In Japan, the level of impaired consciousness is also evaluated using the Japan Coma Scale (JCS), which consists of eyeopening to stimuli, similar to the E component of the GCS. The JCS is widely accepted by paramedics and nurses working in the emergency department, and is reportedly correlated with the GCS [14].

Therefore, when GCS data were missed, we imputed values for mildly impaired consciousness (JCS level $1,1-3$ ), moderately impaired consciousness (JCS level 2, 10-30), and severely impaired consciousness (JCS level 3, 100-300), based on previous reports [8, 9].

\section{Outcomes}

The primary outcome was defined as severe hypothermia at hospital arrival. According to the Swiss staging system, hypothermia was classified as stage 1 (BT: $\left.32-35.0^{\circ} \mathrm{C}\right)$, stage $2\left(\mathrm{BT}: 28-31.9^{\circ} \mathrm{C}\right)$, stage 3 (BT: $\left.24-27.9^{\circ} \mathrm{C}\right)$, and stage $4\left(\mathrm{BT}:<24^{\circ} \mathrm{C}\right)[1]$. For the present study, severe hypothermia was defined as Stage 3-4 cases [1]. The secondary outcome was defined as all-cause in-hospital mortality.

\section{Statistical analysis}

Patient characteristics at hospital arrival were analyzed according to the level of consciousness. Continuous variables were reported as medians and IQRs, and categorical variables were reported as numbers and percentages. As a primary analysis, the association between the level of impaired consciousness and severe hypothermia was evaluated by multivariable logistic model adjusting potential confounders as following covariates that are generally available in the out-of-hospital setting: age, sex, $A D L$, consciousness, systolic blood pressure, and heart rate. Logistic regression analysis was used to evaluate the risk of severe hypothermia $\left(B T:<28.0^{\circ} \mathrm{C}\right)$ according to level of impaired consciousness, and the results were reported as COR or AOR with the corresponding $95 \% \mathrm{Cl}$. Further, we investigated the ability of impaired level of consciousness to predict severe hypothermia was evaluated based on the values for sensitivity, specificity, positive LR and negative LR. As a secondary analysis, the association between the level of impaired consciousness and in-hospital mortality was investigated by logistic 
regression analysis using the same covariates as potential confounders for the primary analysis. All analyses were performed using JMP Pro 14 for Windows software (SAS Institute, Tokyo, Japan).

\section{List Of Abbreviations}

AH: accidental hypothermia

BT: body temperature

Cl: confidence interval

IQR: interquartile range

ADL: activities of daily living

GCS: Glasgow Coma Scale

JCS: Japan Coma Scale

COR: crude odds ratio

AOR: adjusted odds ratio

\section{Declarations}

\section{Funding}

This research received no specific grant from any funding agency, commercial or not-for-profit sectors.

\section{Conflicts of interest/Competing interests}

There are no conflicts of interest related to this research.

\section{Availability of data and material}

All relevant data is included in the report and its related files.

\section{Code availability}

Not applicable.

\section{Authors' contributions}

TM and TK conceived and designed the J-point registry study. MN, YO, SM, NE, NM, TJ, YS, NO, MW, AT, $Y F, Y O$, and TM undertook recruited the participating centers, collected the data, managed the data, and performed quality control. MF prepared a draft of this report. MF and YO analyzed the data and interpreted the results. All authors critically evaluated and approved the report. 


\section{Ethics approval}

The J-point registry protocol and retrospective analysis of anonymized data were approved by the ethics committee of Saiseikai Shiga Hospital (approval ID: 244).

\section{Consent to participate}

Not applicable.

\section{Consent for publication}

Not applicable.

\section{Acknowledgements}

Not applicable.

\section{References}

1. Brown DJ, Brugger H, Boyd J, Paal P. Accidental hypothermia. N Engl J Med. 2012;367(20):1930-8.

2. Matsuyama T, Morita S, Ehara N, Miyamae N, Okada Y, Jo T, et al. Characteristics and outcomes of accidental hypothermia in Japan: the J-Point registry. Emerg Med J. 2018;35(11):659-66.

3. Paal P, Gordon L, Strapazzon G, Brodmann Maeder M, Putzer G, et al. Accidental hypothermia-an update: The content of this review is endorsed by the International Commission for Mountain Emergency Medicine (ICAR MEDCOM). Scand J Trauma Resusc Emerg Med. 2016;24(1):111.

4. Zafren K. Out-of-Hospital Evaluation and Treatment of Accidental Hypothermia. Emerg Med Clin North Am. 2017;35(2):261-79.

5. Podsiadło P, Darocha T, Kosiński S, Sanak T, Gałązkowski R. Body temperature measurement in ambulance: a challenge of 21-st century? BMC Emerg Med. 2019;19(1):44.

6. Niven DJ, Gaudet JE, Laupland KB, Mrklas KJ, Roberts DJ, Stelfox HT. Accuracy of peripheral thermometers for estimating temperature: a systematic review and meta-analysis. Ann Intern Med. 2015;163(10):768-77.

7. Pasquier M, Carron PN, Rodrigues A, Dami F, Frochaux V, Sartori C, et al. An evaluation of the Swiss staging model for hypothermia using hospital cases and case reports from the literature. Scand $\mathrm{J}$ Trauma Resusc Emerg Med. 2019;27(1):60.

8. Okada Y, Matsuyama T, Morita S, Ehara N, Miyamae N, Jo T, et al. Prognostic factors for patients with accidental hypothermia: A multi-institutional retrospective cohort study. Am J Emerg Med. 2019;37(4):565-70.

9. Okada Y, Matsuyama T, Morita S, Ehara N, Miyamae N, Jo T, et al. The development and validation of a " $5 \mathrm{~A}$ " severity scale for predicting in-hospital mortality after accidental hypothermia from J-point registry data. J Intensive Care. 2019;7:27. 
10. Kandori K, Okada Y, Matsuyama T, Morita S, Ehara N, Miyamae N, et al. Prognostic ability of the sequential organ failure assessment score in accidental hypothermia: a multi-institutional retrospective cohort study. Scand J Trauma Resusc Emerg Med. 2019;27(1):103.

11. Ministry of Health. Labour and Welfare. List of Health, Labour and Welfare Statistics. Available: https://www.mhlw.go.jp/toukei/itiran/index.html. Accessed 26 January 2020 [in Japanese].

12. Japan Fire and Disaster Management Agency. Urgency Determination Protocol ver.1.1. Available: https://www.fdma.go.jp/mission/enrichment/appropriate/appropriate002.html. Accessed 17 March 2020 [in Japanese].

13. Striebel HW, Steinhoff U, Krause H, Kretz FJ. The reliability of pulse oximetry monitoring of arterial oxygen saturation in centrally intubated and hypothermic patients. Anasth Intensivther Notfallmed. 1988;23(4):200-4. [in German].

14. Okada Y, Kiguchi T, liduka R, Ishii W, Iwami T, Koike K. Association between the Japan Coma Scale scores at the scene of injury and in-hospital outcomes in trauma patients: an analysis from the nationwide trauma database in Japan. BMJ Open. 2019;9(7):e029706.

15. Deslarzes T, Rousson V, Yersin B, Durrer B, Pasquier M. An evaluation of the Swiss staging model for hypothermia using case reports from the literature. Scand J Trauma Resusc Emerg Med. 2016;24:16.

16. Debaty G, Moustapha I, Bouzat P, Maignan M, Blancher M, Rallo A, et al. Outcome after severe accidental hypothermia in the French Alps: A 10-year review. Resuscitation. 2015;93:118-23.

17. Walpoth BH, Walpoth-Aslan BN, Mattle HP, Radanov BP, Schroth G, Schaeffler L, et al. Outcome of survivors of accidental deep hypothermia and circulatory arrest treated with extracorporeal blood warming. N Engl J Med. 1997;337(21):1500-5.

18. Krantis A. Hypothermia-induced reduction in the permeation of radiolabelled tracer substances across the blood-brain barrier. Acta Neuropathol. 1983;60(1-2):61-9.

19. McCullough JN, Zhang N, Reich DL, Juvonen TS, Klein JJ, Spielvogel D, et al. Cerebral metabolic suppression during hypothermic circulatory arrest in humans. Ann Thorac Surg. 1999;67(6):1895-9. discussion 919-921.

20. Stecker MM, Cheung AT, Pochettino A, Kent GP, Patterson T, Weiss SJ, et al. Deep hypothermic circulatory arrest: I. Effects of cooling on electroencephalogram and evoked potentials. Ann Thorac Surg. 2001;71(1):14-21.

21. Bledsoe BE, Casey MJ, Feldman J, Johnson L, Diel S, Forred W, et al. Glasgow Coma Scale Scoring is Often Inaccurate. Prehosp Disaster Med. 2015;30(1):46-53.

22. Basauhra Singh HK, Chong MC, Thambinayagam HC, Zakaria MI, Cheng ST, Tang LY, et al. Assessing Nurses Knowledge of Glasgow Coma Scale in Emergency and Outpatient Department. Nurs Res Pract. 2016;2016:8056350.

\section{Figures}




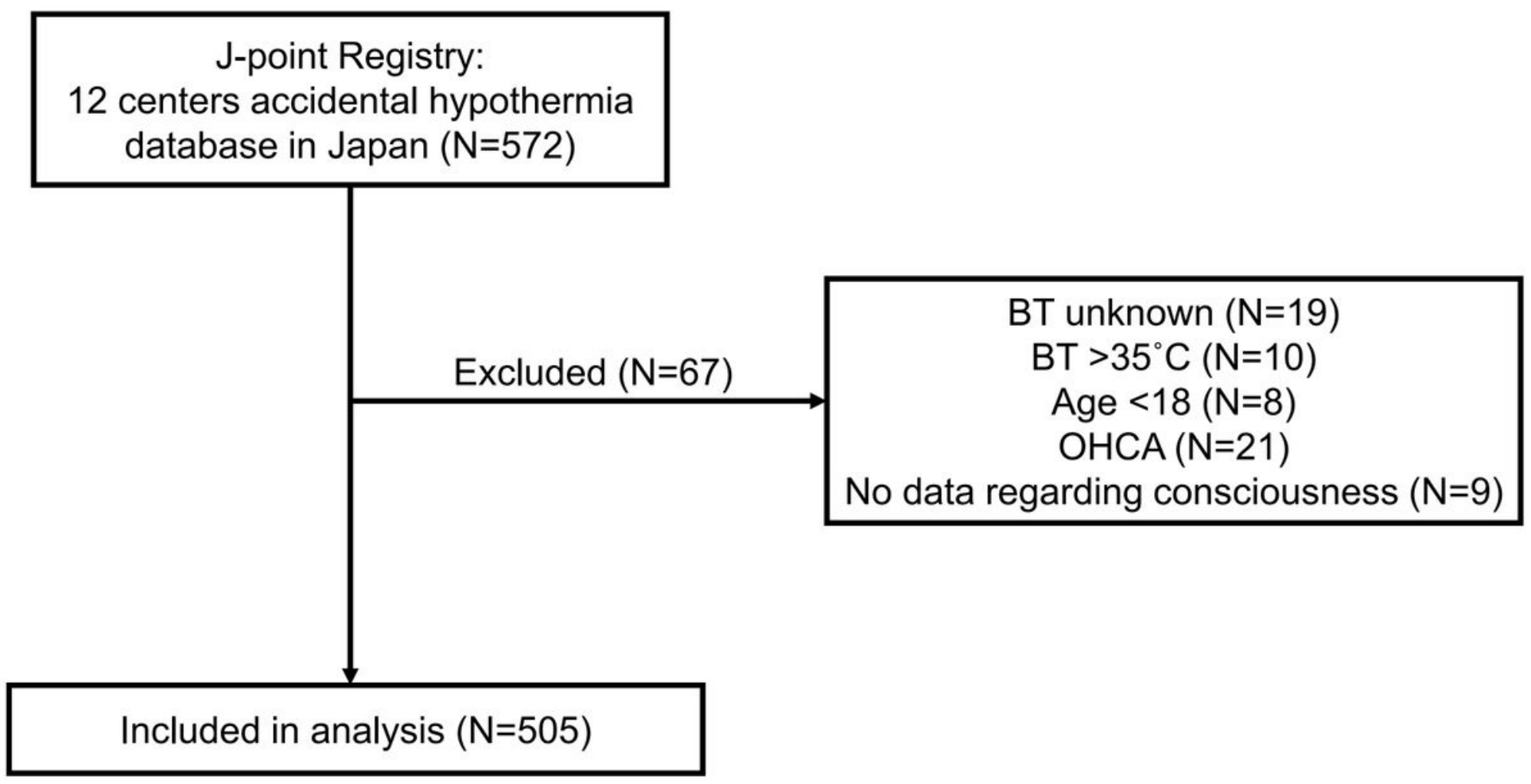

Figure 1

Study flowchart. BT, body temperature; OHCA, out-of-hospital cardiac arrest 


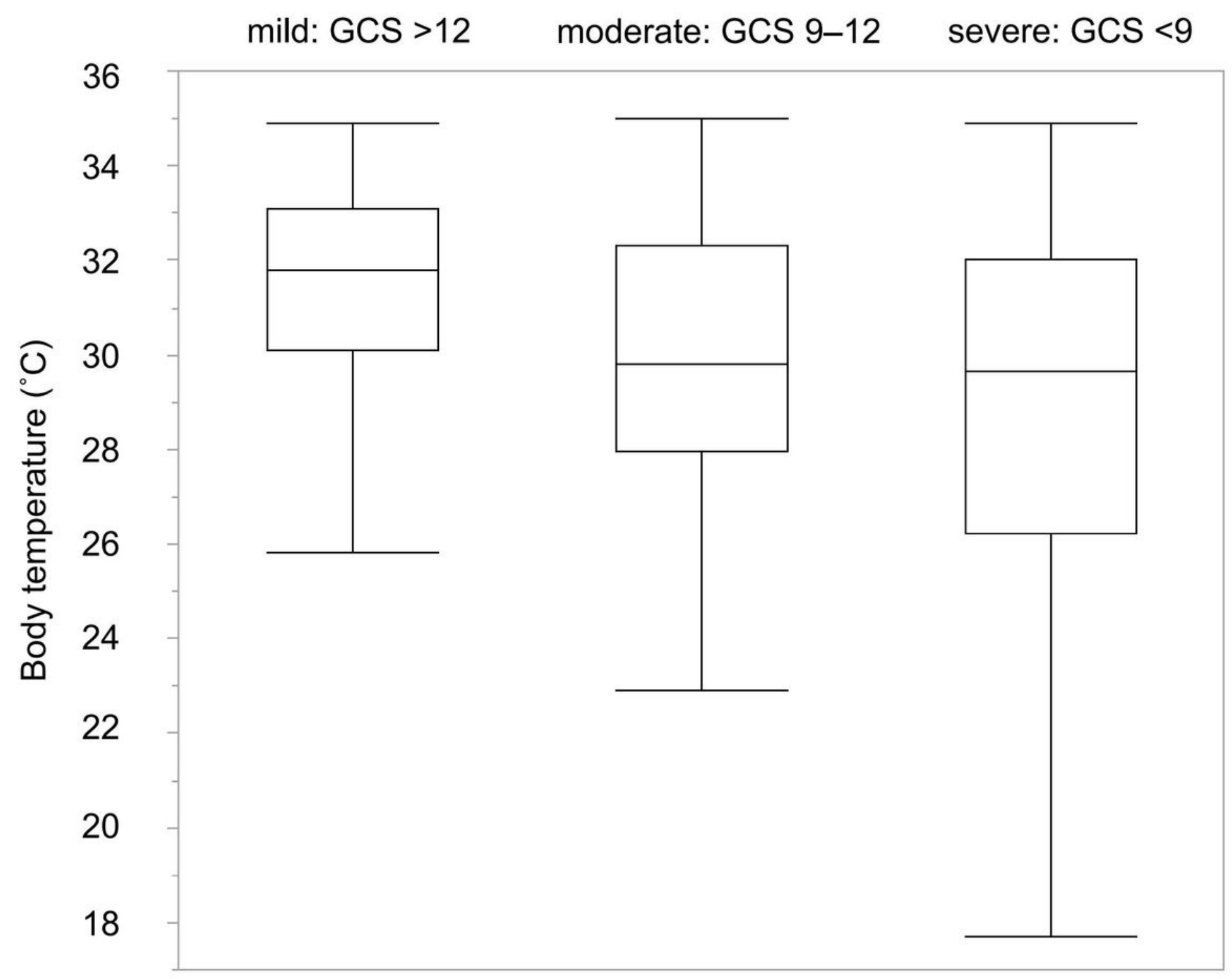

Figure 2

Relationship between degree of impaired consciousness and body temperature. 
In-hospital mortality(\%)

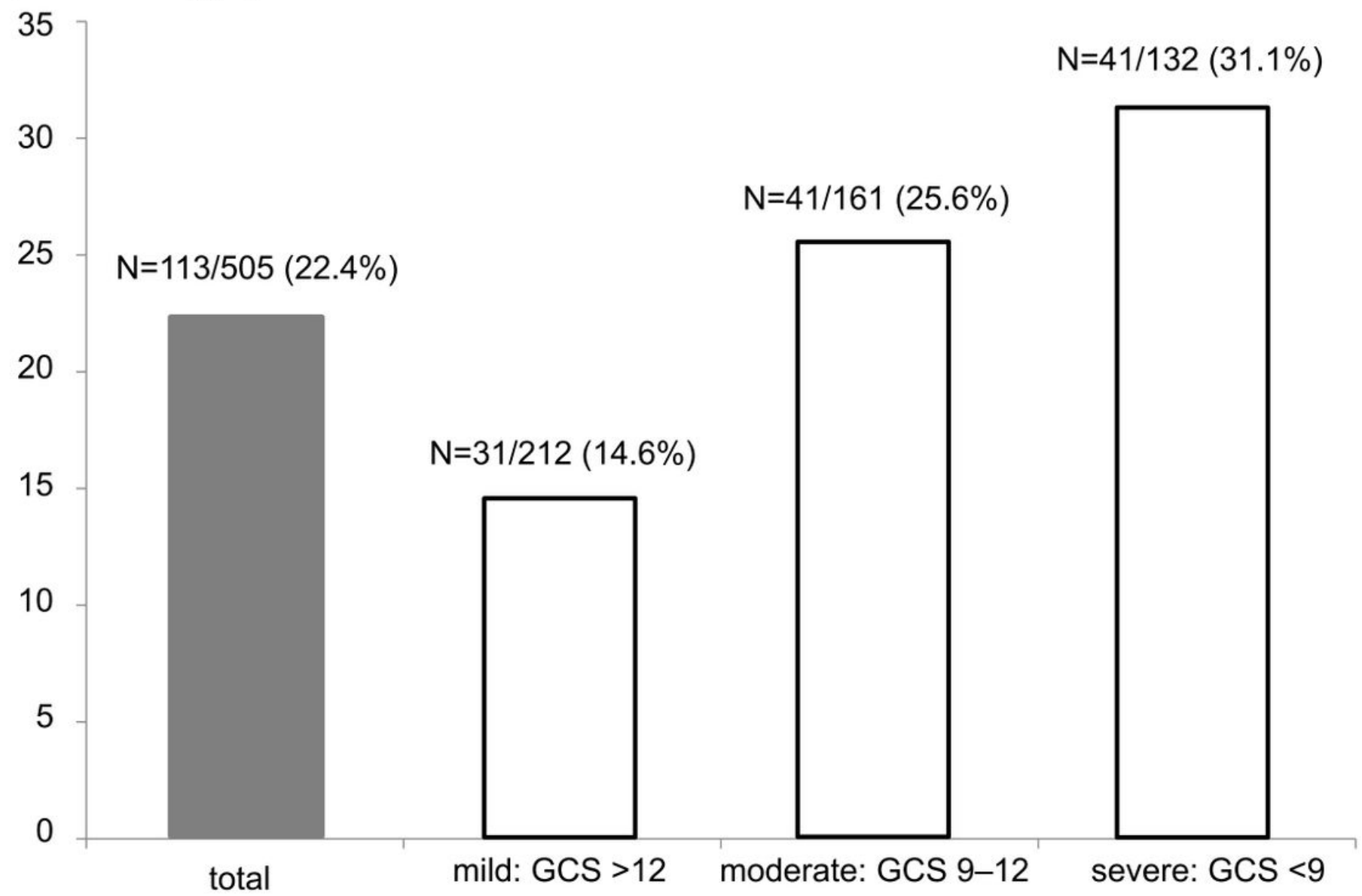

Figure 3

In-hospital mortality according to degree of impaired consciousness. 
AOR $\quad 95 \% \mathrm{Cl}$

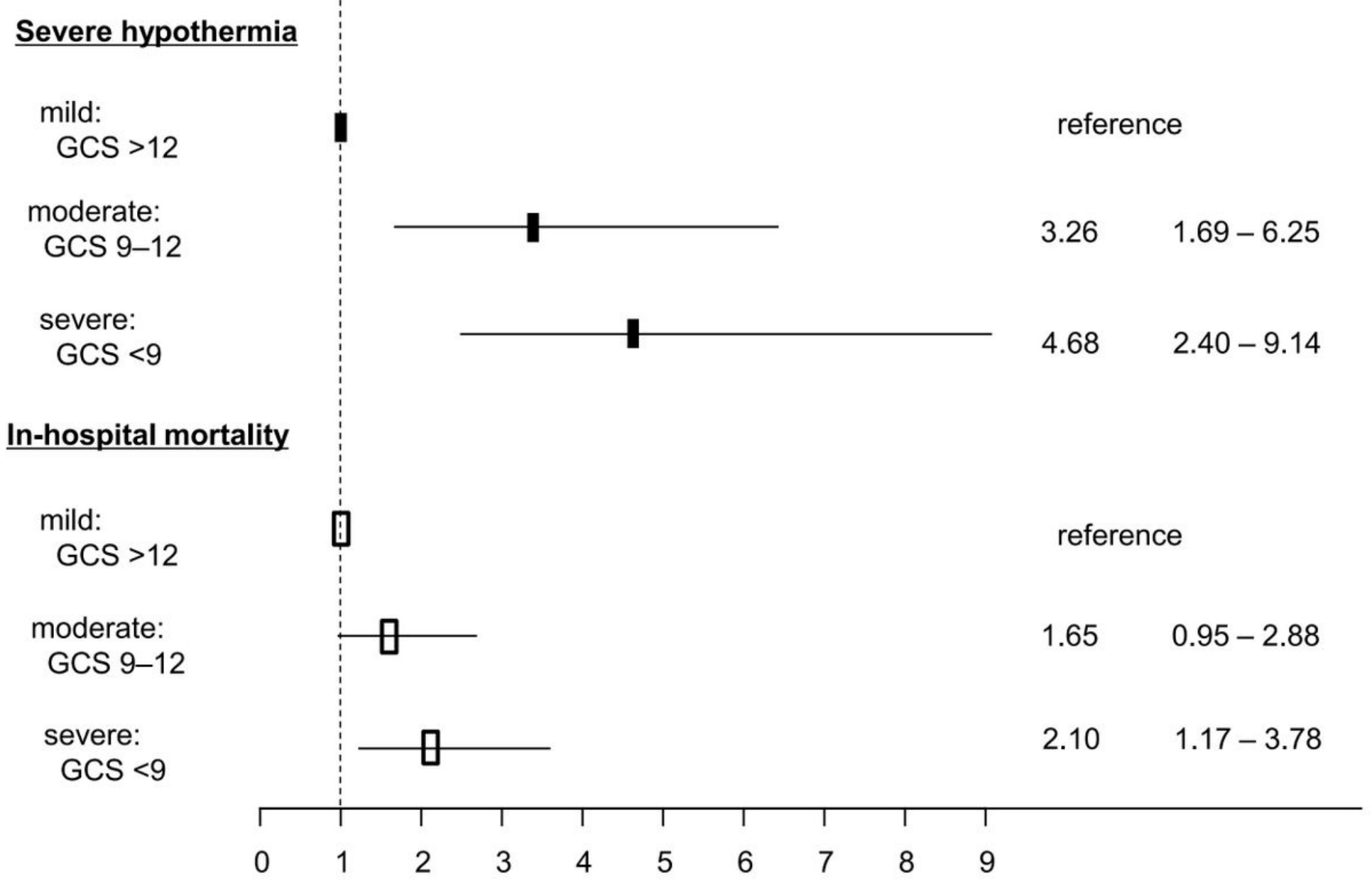

Figure 4

Risk of severe hypothermia and in-hospital mortality according to degree of impaired consciousness 